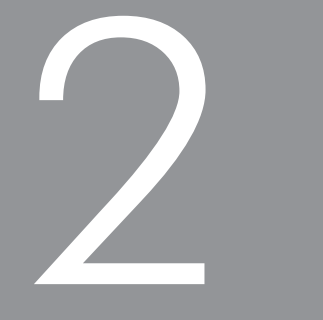

\title{
ACADEMIC DEVELOPMENT IN SOUTH AFRICAN HIGHER EDUCATION
}

Ian $\operatorname{Scott}^{1}$

\section{INTRODUCTION}

What's in a name?

The term 'Academic Development' (AD) has a meaning and set of associations in South Africa that are different from the usage in various other parts of the world, where it refers predominantly to academic staff development.

The term was first used in South Africa in the mid-1980s, but its conceptual origins go back to 1980, to the 'Academic Support Programmes' (ASPs) that were founded in 1980 or shortly thereafter at the English-medium 'liberal' universities². ASPs were established to facilitate the entry and integration of black students into these institutions, which had been statutorily whites-only since the so-called Extension of University Education Act of 1959, so ASPs were centrally concerned with equity of access from the outset. Their work initially included material and general advisory as well as academic support, but progressively concentrated on the academic, mainly in the form of specialised teaching, tutoring and instructional design ${ }^{3}$. These two elements - equity and a focus on the formal educational process - have characterised South African ASP/AD work throughout its history.

1 The author is the Director of the AD Programme at the University of Cape Town. This contribution is thus written from an insider perspective, and it offers a personal view of the field.

2 Wits, Cape Town, Natal, Rhodes.

3 The importance of a holistic view of student development is well recognised, but material support and counselling are more effectively addressed by specialised units. 
The original ASP approach, which addressed the realities of black students as a disadvantaged minority in the institution, was clearly not suitable in historically black institutions ( $\mathrm{HBls}$ ), where educational disadvantage affected almost all students. Thus, as the commitment to dealing with inequalities grew in the context of the political ferment of the mid-1980s, interested academics argued that the position in the HBIs called for improving teaching across the institution, and that the appropriate approach was to focus on staff development. It was in this context that the term AD came into use in the mid-1980s. 'Support' was seen to be too narrow and to have patronising connotations; more importantly, the concept of development was then experienced as forward-looking and positive as opposed to the idea of remediation and its associations of inferiority. Thus ' $A D$ ' in due course became the dominant term for tertiary educational development in the South African context, incorporating the ideas of student, staff, curriculum and institutional development. The HEQC's (2007:74) current definition captures this evolution:

\begin{abstract}
A field of research and practice that aims to enhance the quality and effectiveness of teaching and learning in higher education, and to enable institutions and the higher education system to meet key educational goals, particularly in relation to equity of access and outcomes. Academic development encompasses four interlinked areas of work: student development (particularly foundational and skills-oriented provision), staff development, curriculum development and institutional development.
\end{abstract}

Despite its widening focus, AD has continued to be understood as being fundamentally concerned with equity and redress. Some professionals in the area see this conception as too narrow and limiting, and want the field to be accepted as embracing all aspects of tertiary teaching and learning for all students. To signal this, new terms such as 'Higher Education Development' have come into use. However, distinctions of this kind are likely to become less and less significant because, as this chapter will argue, the field of work represented by these terms must - by its nature and to fulfil its purpose - encompass the full spectrum of the theory and practice of tertiary educational development, and also - given the social and economic imperatives of South Africa must have equity of access and outcomes as a central goal.

\title{
$A D$ as both an issue and a perspective
}

This book aims to 'promote an understanding and appreciation of some important perspectives and issues that shape and drive higher education' (see Bitzer, Preface of this volume). $A$ theme of this chapter is that $A D$, or rather what it stands for, is a central 
and persistent issue in South Africa and at the same time provides a perspective on higher education that contrasts uncomfortably with the dominant ones.

$A D$ has been a significant issue for three decades: a matter of symbolic ideological contestation in the apartheid period and a focus of tension in policy, practice and academic ideology in the democratic dispensation. This is not because of power and influence in the AD community itself - which has largely been marginal - but because of two contentious, interlinked issues that $A D$ has represented: equity and redress in the student body, and the status and significance of teaching in higher education. Under apartheid, the focus of contestation was of course racial equity. Since the political transition, the conflict has been more complex, lying not only in the classic issue of the relationship between equity and 'excellence', but also in the tension between 'teaching' and 'research', as reflected in the issue of academic identity (particularly in the developing-country context) and the priorities adopted by the institutions. These matters are elaborated in sections below.

$\mathrm{AD}$ can also be regarded as a perspective. There has clearly been much change in South African higher education since 1994, but understandings of the nature and effects of the change vary in accordance with the perspective of the observer. Badat (2009) notes the importance of 'interrogating how change at the national level and at the level of institutions has been theorised, and how, in what ways and to what extent the methodological approaches that have been utilised have illuminated and/ or obfuscated the nature and trajectory of change'.

An 'AD' analytical perspective on higher education comes out of engagement with the equity and teaching-and-learning nexus. This lens produces a view of the performance of the system that raises critical questions about the purposes, identity and central obligations of the higher education sector in the South African context. This perspective accepts the conventional understanding of the essential purposes of higher education as being the production and dissemination of knowledge, but challenges the current prioritisation and orientation of higher education's main functions in contemporary South Africa. Key issues include what constitutes 'core business' and who higher education is for. The conditions and analysis that give rise to the AD perspective are outlined in the body of this chapter.

\section{THE ISSUE OF EQUITY: AD AND 'TRANSFORMATION'}

The issue of equity, or 'transformation', in higher education has a range of facets, notably equity in staffing and equity in the student body. Given its purpose, AD has 
always been centrally concerned with equity in the student body, and it is this form of transformation that is focused on in this chapter. (It should be noted, however, that representivity in staffing has also been an important consideration in $A D$ in the historically white institutions, as an end in itself and also as a means of facilitating student equity because of the importance of role models and diverse voices in the academic community.)

For many in $A D$, the essence of transformation is inclusiveness in who benefits from higher education. This broad idea of transformation encompasses indirect benefits the role of advanced knowledge and research in improving and enriching the country as a whole - as well as the benefits of participating directly in higher education. In this view, student equity is arguably the central way of bringing about progressive and sustainable transformation, through individual empowerment and harnessing the talent in all communities, which in itself should have far-reaching effects on development and the setting of the development agenda. It follows that equity of outcomes is as important as equity of access. While the term 'equity of outcomes' became current only in 1997 through being used in the higher education White Paper (DoE 1997), it had long been recognised in AD that access without success would be a meaningless achievement. The importance of equity of outcomes has profound implications for how educational development policy and practice should be conceived of and evaluated.

AD's primary site of work is the formal educational process in higher education in all its facets, from student selection and placement to curriculum design to practice in the classroom. Teaching-and-learning development is thus the main area of AD practice and research, along with the policy and institutional development work that is needed to provide space and resources for this. While this section focuses primarily on the equity issue, the close linkage with institutional attitudes to teaching and learning will be evident, and will also be discussed specifically later.

Detailed periodisation and analysis of the evolution of $A D$ are beyond the scope of this chapter, ${ }^{4}$ but the following sub-sections aim to outline how key focal points of $A D$ research and practice have evolved, and to suggest where AD must go if its underlying goals are to be achieved.

4 For an account of the evolution of $A D$ as experienced in one institution, see Scott et al. 2005. 


\section{AD UNDER APARTHEID: THE EVOLUTION OF KEY THEMES}

The institutional contexts into which ASP/AD was introduced in the 1980s were highly varied, within as well as between the broad categorisations that were current, viz. the 'liberal' universities, the 'Afrikaans' universities and technikons, and the historically black institutions. As is well known, relative to the population there were few black students enrolled in the sector, only a few hundred in each of the liberal universities and almost none in the Afrikaans institutions ${ }^{5}$. There was no government support or funding for $A D$ work, and attitudes to it within the institutions were very uneven pockets of support alongside much ambivalence or hostility (see for example Vilakazi and Tema 1985; Hofmeyr and Spence 1989) - reflecting the full spectrum of political and academic ideology. It was a difficult but rich period, still relatively unexplored analytically. For the purposes of this chapter, two key features of AD work that emerged in this early phase merit discussion.

\section{Recognition of the systemic nature of the equity challenge}

In the 1980s (and indeed well beyond) mainstream understanding of the challenges of equity and educational disadvantage might fairly be described as superficial or minimalist. In the liberal universities, ASPs were initially modelled on North American minority programmes. It was generally thought that all that was needed, and justified, was more of what the traditional students were given, that is tutorial support, together with some language intervention for English second-language students. In fact, on the grounds of perceived threats to academic standards, AD interventions were generally required to be of limited duration and intensity lest the students should be 'coached through'.

From early in the 1980s, however, academics in AD began to understand the complex nature of educational disadvantage in the South African context. They became conscious that there were major systemic obstacles to black students' succeeding in any substantial numbers in the historically white universities. In addition to the effects of language and socio-economic conditions, a key factor was a crippling combination of poor schooling and higher education curriculum parameters that had been designed decades before for a homogeneous, largely privileged student intake. This mismatch, or articulation gap, between secondary and higher education had the consequence that the assumptions about prior learning that underlay the traditional curricula were

5 As late as 1988, black (African) students made up only $10 \%$ of headcount enrolment in the liberal universities, only $1 \%$ in the Afrikaans-medium universities, and $32 \%$ in the sector as a whole (Cooper and Subotzky 2001). 
not valid for the great majority of black students. Unless the schooling available to the majority were to be drastically improved, black students - all but the most exceptionally talented - would continue to be denied the opportunity to realise their potential, because the tertiary educational process made no allowance for diverse educational and socio-cultural backgrounds.

It was this understanding that led to the development, as early as 1982-1983, of 'foundation' courses in key subjects, designed specifically to fill in the articulation gap with tertiary-style provision (rather than by re-doing school work). By the mid1980s, despite a total absence of state support and funding, such courses were being organised in coherent 'foundation programmes' attached to specific degrees in innovative ways that matched particular contexts. The range of models is exemplified by the Science Foundation Programme at Pietermaritzburg, the UNIFY programme at the University of the North (now Limpopo), the College of Science at Wits and ASPECT in Engineering at UCT, which addressed significantly different institutional and faculty contexts and intake profiles (Hofmeyr and Spence 1989). There were also inventive and pioneering initiatives that focused primarily on new approaches to secondary and further education provision, designed to bridge the gap from the other side, as it were. Most prominent among these was the Career Preparation Programme, expertly and adroitly devised by Kalie Strydom and colleagues at the then University of the Orange Free State (UOFS) to be workable in what was an unusually difficult environment for promoting equity. $A D$ was, and is, very much the art of the possible.

These models, and the many others that were successfully implemented, were necessarily distinctive because of their different contexts, but all had in common that they addressed the key systemic problem of the articulation gap. They were thus based on curriculum development designed to accommodate diversity, and this has been a characteristic feature of almost all successful AD initiatives ever since. However, AD specialists recognised, as early as the mid-1980s, that there were key problems with foundational interventions and that they were a necessary but not sufficient condition for equity. Foundation programmes were marginalised and served only a minority of the student intake (and were thus vulnerable to stigmatisation), yet the problem they were designed to address affected the majority of the population. Moreover, while every effort had to be made to improve schooling, the resources available in a developing country would almost certainly never be sufficient for the mass school system to be able to produce substantially more matriculants with the level of preparedness that traditional higher education programmes assumed to be in place. Thus the need for intervention was not going to diminish. 
It therefore became evident that equity would not be attainable until mainstream higher education curricula and teaching approaches developed the capacity to accommodate talented students from all communities and educational backgrounds (see for example Moulder 1991; Hunter 1991; Scott 1986). However, the gap between recognising this goal and realising it was dauntingly wide. Resistance to this kind of change was deeply embedded, not only in government (where the dominant position changed in 1994), but also in the higher education community itself (where conservative academic orthodoxy has persisted). These conditions produced two lasting responses in AD: a focus on working towards policy change, initially in the institutions and later in the state; and, especially in the historically white universities, a growing concern with systemic issues, such as the articulation of foundation courses with mainstream programmes (for which a number of innovative models were developed) and, later, the use of AD initiatives as sites for developing educational approaches that could accommodate talented but underprepared students and might in time be used to accommodate student diversity in mainstream programmes.

In the then-black institutions, the underlying $A D$ challenges were similar, but the focus on systemic issues came about via a different route. Since the main contextual difference was that the great majority of the students were from disadvantaged backgrounds, 'minority' approaches did not make sense, so the emphasis came on to staff development in a range of forms, aimed at encouraging mainstream academics to improve their teaching. While much good work was done, the strategy was obstructed by two main problems. First, the difficulty of achieving staff engagement was great. Second, the articulation gap was as big an obstacle as in the historically white institutions since, despite the majority of the intake having always come from disadvantaged backgrounds, the $\mathrm{HBls}^{6}$ had adopted the traditional South African curriculum structures. With some notable exceptions such as the UNIFY programme, the HBls did not focus on curriculum restructuring or foundational provision, perhaps because of the scale of the challenge. Unintentionally, this provided a 'control group' of a sort: despite all the AD efforts made to improve mainstream teaching, widespread and substantial improvement in student performance patterns did not materialise. This suggests that in the South African context, focusing only on 'teaching better' within the existing, flawed curriculum parameters is not an adequate response to the equity challenge.

6 An exception was the University of Bophuthatswana, which initially followed an innovative four-year degree structure. 
Thus key themes that emerged during the apartheid period included:

- recognition of the systemic origins of the obstacles to equity;

- the understanding that, not being a minority or ephemeral phenomenon, educational disadvantage and inequity could not be effectively addressed in South Africa by minority programmes, 'band-aid' approaches or initiatives on the fringes of the institutions or the sector; and

- the consequent need for change in the educational process in higher education ultimately in mainstream structures and practices - rather than an exclusive focus on schooling.

The emergence of these issues in the 1980s marked the beginnings of a decades-long effort to gain recognition of the need for mainstream educational reform, as outlined below. The persistence of these themes has had a major bearing on AD practice, research and policy-related work.

\section{The identity and role of AD: Tension between 'activist' and 'academic' orientations}

One effect of the essentially political nature of the origins of AD was that many of the people who were attracted to work in the field, particularly in its early stages, were motivated by strong social-change agendas. Some came from junior or temporary posts in regular academic departments, others from schools or private-sector organisations which offered little opportunity to express opposition to the political status quo. The nature of the staff and of $A D$ work at the time, often involving close relationships with students in the van of mass political action, established an activist rather than conventional academic ethos in many AD units. The intense political turmoil and violence of the 1980s directly affected many AD staff and radicalised them further, creating tensions between $A D$ and regular departments particularly in the historically white universities. A result of the unconventional orientation of $A D$ was that much innovative teaching-and-learning work was not conventionally researched or published, and AD-related analysis for policy remained largely in institutional documents or conference proceedings of the emerging professional association, the South African Association for Academic Development (SAAAD). The substantial gaps in $A D$ literature have hindered research, and together with discontinuities in staffing due mainly to breaks in funding, have contributed to a failure to build on past experience that has unfortunately characterised AD work in a number of institutions. 
However, even in the 1980s the need for AD to be theorised and systematically informed by international thinking was increasingly strongly experienced. Putting AD on a firmer academic base was seen to be important for the work itself, but also necessary for influencing the academic community and institutional (and later national) policy. The flavour of the early thinking is perhaps best captured in Merlyn Mehl's (1988) 'Academic Support: Developmental giant or academic pauper?' So, by the latter years of apartheid, vibrant theoretical debates on matters of learning, such as the nature of educational disadvantage in the South African context, were under way, informed by the work of a range of theorists such as the psychologists Vygotsky, Piaget and Feverstein, Bourdieu and various social theorists, Perkins, Cummins and many others in Applied Linguistics, and to some extent the phenomenography movement ${ }^{7}$. The flavour of formative South African perspectives is interestingly illustrated in contributions to the 'Salt Rock' workshop in 1988, 'New students in old universities' (Lazarus et al. 1989). Issues of AD identity and its role in institutional and social change were hotly contested (see for example Vilakazi and Tema 1986; Moulder 1991; Hunter 1991), but also located in change theory (see for example Agar 1994). Under apartheid, policy work, aiming to raise awareness of the equity issue and create space for AD work, was focused on institutions since there was no prospect of any government support.

A significant point is that some of the various specialised groupings within or associated with $A D$ have strong academic identities of their own. Prominent among these are 'Language Development', which focuses on key issues arising from the fact that the majority of South African students do not have English (the dominant medium of instruction) as their first language, and is located in Applied Linguistics; and (tertiary) Science Education, where, notwithstanding much common ground, there have been particular tensions between conventional academic positions and the 'political' side of AD. The area of 'alternative admissions' and assessment for student selection, while strongly organically connected with $A D$, also has a distinctive identity and discourse.

While its form has changed since the political transition, the underlying tension within the identity and role of $A D$ has to some extent persisted, and continues to influence practice and research. Teaching in all its various forms is at the heart of $A D$, but the primary tension - often creative, sometimes not - lies between a more conventional academic approach, expressed in research and publication in scholarly media, and a 'developmental' approach, focused on policy change, implementing interventions and engaging the state, the institutions and the academic community. These approaches

7 See References for a few examples of works by these theorists that were influential in AD. 
should of course be complementary, but in practice there is contestation about whether standard educational research is having (or should be expected to have) a discernible impact on mainstream practice, about what constitutes a valid academic basis for developmental interventions, and about the relationship between the academic role and the professional service responsibilities of $A D$ in the institution. This tension is experienced in other countries as well, but is perhaps more acute in the context of South Africa's urgent need for change.

A related matter is AD's relationship with what Clegg (2009) terms 'more radical pedagogies'. From an early stage, a number of AD specialists have been interested in approaches to curriculum and teaching and learning that are alternative to and sometimes fundamentally different from the dominant traditional ones. Interests have ranged from socio-politically radical approaches like Freire's, through issues of programme identity and content like the 'Africanisation' of curricula, to alternative pedagogies like problem-based learning and other manifestations of constructivist learning theory. Many AD staff have incorporated aspects of such approaches into their own (student- or staff-facing) teaching and development work, but influencing mainstream practice is clearly of a different order of complexity. By and large, except in the rare cases where a mainstream discipline is supportive of substantial change in orientation, AD units have focused their attention on the teaching-and-learning aspects of educational development where they have judged progress with inclusiveness can be made. Nevertheless, working within curriculum orientations with which they do not personally identify, has been and will no doubt continue to be a difficult matter for AD specialists. The topic is referred to again later in this chapter.

In some respects the tensions within $A D$ reflect wider dilemmas about the identity and role of academics and universities in South Africa's developing-country context. The way these dilemmas play out has major implications for the goals of equity and development, as will be discussed below.

\section{AD IN THE DEMOCRATIC ERA: THE TENSION BETWEEN EQUITY AND DEVELOPMENT}

In the run-up to the political transition in 1994 and for some years thereafter, there was an unprecedented opportunity for $A D$ to engage with national education policy, which was being radically re-engineered. The new government clearly identified with the goal of equity, which became one of the main pillars of higher education policy (DoE 1997). However, the tensions involved in real-world policy making soon made their presence felt. There were enormous pressures on the Department of Education (DoE) to 'do 
everything', to satisfy the wide range of stakeholders and competing expectations. In particular, the essential academic conservatism of the higher education sector and traditional views of its contribution to society came into conflict with an overwhelming demand for admission to higher education from black students, who had historically been largely excluded.

It was in such conditions that Wolpe et al., in the early 1990s, articulated the tension between 'equality' and 'development', the latter referring to the rigour, standards and competitiveness needed for economic as well as social development (Wolpe, Badat and Barends 1993). This conceptualisation, in its broadest form and in different manifestations, has remained a valid characterisation of the central tension in South African higher education policy and practice, and has far-reaching implications for $A D$ work and research. In these circumstances, AD has seen its fundamental goal to be promoting a fair and productive balance between equity and development, which has in turn meant trying to ensure that the equity goal is not submerged by traditional academic culture, and that educational approaches are developed that enable greater inclusiveness to be achieved without devaluing the currency of academic quality. As a means to this end, it has been critical for $A D$ to overcome its marginalisation, to gain space and support for educational development through recognition and secure resourcing.

$A D$-oriented academics have consequently been involved in various forms of national education policy development over the last two decades, in a long-term effort to give concrete expression to the goal of development with equity. Fortunes have been mixed, but key milestones have included the following:

- contributions to the National Commission on Higher Education (e.g. SAAAD 1995) that resulted in the first state recognition of $A D$ in the higher education White Paper of 1997. The White Paper's coverage of AD was brief, but critically included a commitment to funding $A D$ interventions - particularly foundational provision within 'extended curriculum programmes' - as 'integral elements of a higher education system committed to redress and to improving the quality of learning and teaching' (DoE 1997:Section 2.34);

- emphasis in the 2001 National Plan on Higher Education on the role of AD and extended curriculum programmes as a central means of facilitating equity of outcomes rather than only of access - this being a critical evolution of the policy understanding of AD (DoE 2001:Section 2.3.2); 
- the inclusion of earmarked funding for $A D$ in the new higher education funding framework of 2003 and the consequent introduction of 'foundation grants' to cover previously unsubsidised foundational provision within extended programmes (DoE 2003; 2006).

Recognition and funding took many years of stop-start progress to put in place, but have been instrumental in extending AD work to institutions that had not been involved, and strengthening it where it was already established. The funding arrangements have kept the focus on alternative curriculum development. A range of extended curriculum programmes have been developed that interweave foundational and mainstream provision in innovative ways (for example, the College of Science at Wits and the Commerce and Science extended programmes at UCT). Unlike the original preparatory foundation-year model, these programmes do not leave the traditional curricula intact, but increasingly problematise them and their capacity to accommodate educational diversity. In addition to AD work on the ground, theoretical knowledge and research have grown strongly this decade, and a number of AD specialists now contribute to international scholarship in higher education studies.

However, AD and what it stands for have remained largely on the margins. Apart from the growth of extended programmes - which, however, still accommodate only about $10 \%$ of the student intake and are very uneven in quality - there has not been significant systemic change in the educational process. Besides the still-small Quality Promotion and Capacity Development Directorate of the HEQC, there are no state-supported agencies or networks for promoting research or professional development in teaching and learning. While there have been major changes in access - black African students now make up over 60\% of headcount enrolment (DoE 2009) - there is widespread experience of failure in many undergraduate courses. Given the importance of higher education to the country, it is essential to monitor its outcomes across all institutions so that the contribution of the sector as a whole can be critically assessed. The following section offers an outline of recent research findings on the sector's performance in undergraduate education, and of some key implications.

\section{PROGRESS TOWARDS EQUITY AND DEVELOPMENT? HIGHER EDUCATION PERFORMANCE IN THE $2000^{5}$}

It is only in the last five years that longitudinal sector-wide student performance data have become available that can provide a basis for such monitoring. The data concerned take the form of cohort studies of the first-time-entering student intake in 
a given year, produced by the DoE. The studies track the performance of all students in the intake until they graduate or leave their original institution without graduating, for a maximum of five years. The cohort studies for the year 2000 and 2001 intakes (the latest 'completed' cohorts at the time) were made available to a CHE-sponsored project, Improving Teaching and Learning for Success (ITLS), for in-depth analysis including disaggregation by race, subject area and institutional type. The following summary of key aspects of undergraduate performance is drawn from the ITLS analysis of the 2000 cohort of which the main patterns have been confirmed by later cohort analysis. ${ }^{8}$

- Performance in the sector as a whole shows very high attrition. After five years, only $30 \%$ of the cohort had graduated. If the optimistic assumption is made that $70 \%$ of students transferring to other institutions and of those still registered after five years will eventually graduate, the final completion rate will still not exceed $45 \%$.

- High attrition occurs in a number of countries, but commonly in an environment of high participation. It is critical to consider performance in South Africa against its participation rates. On the UNESCO measure of Gross Enrolment Rate $(G E R)^{9}$, developed countries range from about 60\% to 90\% (UNESCO 2007), while South Africa's rate is $16 \%$ (against a benchmark of $20 \%$ for countries at a comparable stage of economic development). Of at least equal concern are the racial discrepancies in participation: whites are at $60 \%$ and black Africans at $12 \%$. Key implications include (a) that it is vital for the higher education sector to be able to accommodate a substantially higher proportion of the country's majority population group, and (b) that the current black intake represents a highly selected group - by and large the top decile of the age group in terms of achieved performance - and thus must be expected to have strong potential to succeed. The common academic staff view that large numbers of the student intake are 'not university material' errs in conflating academic preparedness with potential, and is belied by the participation rates.

- Poor performance is widespread. The traditional contact university degree programmes - primarily the three-year Bachelor's and the highly selective fouryear Professional Bachelor's programmes - make up the best-performing subsector, but even there the cohort graduation rate after five years is only $50 \%$. In the

8 For the full study, see Scott, Yeld and Hendry (2007), aspects of which are elaborated in Yeld (2009) and Scott (2009b and c).

9 The GER represents total enrolment (of all ages) expressed as a percentage of the 20-24 age group in the population. 


\section{PART ONE - ISSUES OF POLICY}

former technikon programmes (now offered in the universities of technology and the comprehensive institutions), the rate is $32 \%$.

- Equity of outcomes is in many respects the central challenge. In key contact university programmes, black completion rates are less than half of the white rates, resulting in the absolute number of black graduates being less than the number of white graduates. Lack of equity of outcomes is thus neutralising the gains made in access. The net effect is that less than $5 \%$ of the black age group is succeeding in higher education in South Africa. ${ }^{10}$

These patterns have major implications for all forms of development, and should be central to the evolution of the AD agenda. Key implications include the following:

- Graduate output is far from meeting national needs in respect of either equity or development.

- The current system is above all not meeting the needs of the majority - the majority population group as well as the majority of the student intake.

- The equity and development agendas have converged. Given the quantitative data, it is clear that the substantial graduate growth needed can come only from the historically disadvantaged groups. Thus catering successfully for student diversity has become a necessary condition for economic development as well as for social inclusion.

- Given the participation rates, access remains an issue, but further enrolment growth will only worsen performance unless the system becomes more effective.

- Substantially improving the performance of the majority of the student intake primarily black and coloured students - is the key to improving overall performance, but it is these groups in particular that are not being successfully catered for in the current mainstream system.

- The scale of the challenge highlights the inadequacy of the scale of current AD work. The main systemic interventions, extended curriculum programmes, have served to increase the number of black graduates in many fields, but their effectiveness continues to be restricted inter alia by the difficulty of integrating them with rigid traditional mainstream curricula and teaching approaches, their marginal status

10 It is interesting to compare this with the average GER of $5 \%$ in sub-Saharan Africa (SSA) as a whole (Unesco 2007). There are no reliable data on SSA success rates but, given the very selective nature of universities in most African countries, graduation rates may be higher than those in SA. Graduate production in SSA as a whole may therefore be only one or two percentage points behind that of the majority population group in SA. 
and consequent lack of capacity and resources in a number of institutions, and their limited reach (some 10\% of the intake).

Given the significance of good higher education outcomes for the country, it is essential to analyse what can be done to improve them. This is a complex topic, but the salient points of an $A D$ perspective can be outlined here.

First, the major effects of the legacy of apartheid, socio-economic inequalities and the state of the school system are not in dispute. However, if we are to depend on change in such external factors to address the problem of graduate output, it is important to analyse the prospects of substantial improvement in these areas. The conclusion is that there is little prospect of such improvement. Socio-economic disadvantage is persistent, and analyses from various perspectives (see for example Van der Berg 2004; Bloch 2008; Yeld 2009) point to the probability that substantial improvement in the outcomes of the school system cannot be expected for a generation or more.

Higher education therefore faces a choice: to accept the status quo as unavoidable for the foreseeable future - in which case the failure to adequately develop the country's talent will continue - or to seek to identify factors that are within the sector's control, and purposefully address these. In AD experience, key among these factors is the educational process in higher education itself. As demonstrated by systemic interventions such as foundational provision (and similar experiences in other countries, such as in community colleges in North America and 'foundation' degrees in the UK), the design and implementation of the teaching-and-learning process is in itself a major variable influencing who succeeds. Doing things differently can enable higher education participation to be successfully widened.

This represents the central educational challenge for AD and the sector as a whole: to develop and implement educational structures and teaching-and-learning approaches that can meet the needs of the majority of the (needed) student intake - now and in the future context of increasing need for growth - and are also flexible enough to successfully accommodate the high level of diversity of educational background that will continue to characterise the system, so that well-prepared students are not artificially held back. Proposing this focus on educational effectiveness is not intended to make light of the issues of content, canon and orientation in the curriculum, or the influence of these on inclusiveness and outcomes. It is contended, however, that creative curriculum ideas will have little or no effect if the educational framework and approaches of the higher education process are not aligned with the actualities of the students' learning needs. 
The sector's capacity to meet its core educational challenges depends greatly on raising the level of effort and expertise in this area, as is discussed in a later section.

\section{AD IN THE 20005: BROADENING THE AGENDA}

How then has AD work responded to these conditions over the last decade? Despite the major contextual changes that have occurred, the challenges are essentially the same as they have been since the inception of $A D$, though now more sharply delineated. It is therefore not surprising that the need for $A D$ work at national and institutional levels continues. However, growing concern about student performance - particularly in national bodies such as the DoE, CHE and JIPSA (2006) as well as in some institutions - has increased the need and opportunity for focusing on mainstream educational development, i.e. designing and implementing structures and approaches intended to improve the effectiveness of teaching and learning across the institution. As outlined earlier, this goal, in various manifestations, has a long history in AD, but has rarely had widespread support from regular academic staff or led to any substantial changes in mainstream practice.

Purposeful, credible and professionally accountable commitment to mainstream educational development has considerable implications for the identity, organisational location and knowledge base of AD. It does not mean a departure from AD's central concern for equity-related development - as the figures show, enabling historically disadvantaged student groups to realise their potential remains the key to improvement in the sector as a whole - nor from the specialised curriculum design and teaching that has been at the heart of $A D$ in many institutions. Dedicated work of this kind has constituted $A D^{\prime}$ 's main laboratory where theory, practice and research can come together and where success is fundamental to AD's credibility. It does, however, call for a strengthened commitment to research-informed development, professional responsibility, and the ability to engage the cooperation and trust of academic colleagues at all levels of the university, primarily through scholarship and demonstrably good practice.

The nature and level of sophistication of AD work has continued to be uneven across the sector, not least because inadequate and insecure funding has discouraged career commitment and research specialisation among staff. However, the following examples of work undertaken in recent years are indicative of the trend in the AD agenda. 
As argued earlier, the significance of systemic change, and consequently of national policy development, is as great as ever. At this macro-level, AD-related policy work has focused on three inter-related areas:

- Curriculum: In addition to ongoing work with the DoE on the design and funding of extended programmes, there is widening debate on the need for and feasibility of curriculum reform. The Minister of Education has consequently requested the $\mathrm{CHE}$ to undertake a comprehensive study of this issue. The main driver of the reform initiative is the importance of creating more curriculum space, both to allow for accommodating the realities of the student intake within a flexible framework, and to enable undergraduate curricula to respond to the increasingly complex demands of the contemporary world - including, in South Africa, preparation for informed and responsible citizenship - without diluting core disciplinary knowledge. $\mathrm{AD}$ identification with both these key aspects of systemic educational development is a good illustration of the broadening of the AD agenda.

- Student selection and 'placement': This strand of AD cannot be discussed here except to note that it is an essential complement to curriculum-based educational development. AD work in this area has focused primarily on (a) identifying students who have the potential to succeed in higher education, but because of their educational background do not perform well in standard school-leaving assessments such as the National Senior Certificate, and (b) gaining an understanding of students' levels of preparedness that can inform the key process of guiding them into the level of introductory provision that will best meet their learning needs. The import of this work for developing the country's talent should be clear. There is a 20-year history of $A D$ work in this area, the most recent manifestation of which is the development of the National Benchmark Tests initiative in cooperation with national bodies, notably Higher Education South Africa (HESA) which is the representative body of the universities' leadership.

- 'Teaching development': The effectiveness of course design and teaching on the ground in the institutions is of course at the heart of the wider educational development agenda. While teaching approaches are not and should not be prescribed nationally, a major shortcoming in South Africa is the absence of any state-supported bodies or networks dedicated to supporting the development and dissemination of teaching-and-learning strategies that are effective for this context. The AD community, through senior individuals and its recently established professional association HELTASA (Higher Education Learning and Teaching Association of Southern Africa), has become increasingly involved in working for 
development in this area, including through participation in the DoE's task group on the Teaching Development Grant, a significant element (R300m-R400m p.a.) of the higher education funding framework, the strategic use of which is being conceptualised at national level. Development in this area could have a real impact on mainstream practice, and is a key and growing element of the AD agenda.

At the institutional level, the role of $A D$ differs markedly across universities, in a number of which it carries very limited influence. However, the process of maturing and broadening is evident in some key cases of cooperation between education development specialists and regular academic departments or faculties in mainstream curriculum development. Notable among these are major initiatives undertaken in recent years in Health Sciences, where as part of an international trend curricula are being radically renewed to adopt a Primary Health Care orientation, with in some cases a simultaneous shift to problem-based learning. The complementary knowledge and experience (and sometimes project management role) of the educational specialist becomes an integral and accountable part of the development process. In some recent projects, in an interesting departure from most historical AD contributions, the role of the educationist - where they have the necessary knowledge of the field - has not been content-neutral. This kind of project has provided strong indications of the value of complementary knowledges and expertise - in the relevant core disciplines, in research-informed curriculum design, and (in the South African context which has to cater to a range of linguistic backgrounds) in areas such as Language Developmentin the development and teaching of academic programmes that have to meet complex contemporary needs and accommodate a diverse student body. The various specialisms are not found in one person, hence the value of a team approach, especially if it is mutually educative.

Perhaps as a consequence of $A D^{\prime}$ s changing profile, renewed critiques of its role are emerging. In a challenging comparison of $A D$ in South Africa and the UK, Clegg (2009:x) raises the issue of the relationship between AD and radical pedagogies. Part of her argument is that in [AD's] constituting teaching and learning as its object other more radical, feminist, and critical pedagogies, which are capable of dealing with the power and curricula, were marginalised.

As noted earlier, related issues arose as early as the 1980s, when a number of AD units took strategic decisions to avoid overtly taking sides in struggles over curriculum content and orientation in order to concentrate on working with the departments on equity and inclusiveness. In South Africa, the question of the extent to which inclusiveness involves 
changing the content and orientation of the curriculum has been vexed and dependent on disciplinary context: think of Physics and English Literature, for example. A related issue is that most recently expressed by Boughey (2008), who critiques the $21^{\text {st }}$ century role of $A D$ as supporting the neo-liberal project as it is manifested in contemporary higher education in South Africa. This issue also has a long history, originating in the context of the struggle against apartheid in the 1980s with political critiques of $A D$ as reformist and insulating the educational establishment against change (see for example Lazarus et al. 1989; Vilakazi and Tema 1985) - critiques that were sharpened by the slogan 'No education before liberation'. These issues will no doubt continue to be important and controversial, and will be all the more pointed as opportunities arise (as in the Health Sciences example noted above) for AD specialists to have a voice in the orientation as well as the educational approaches of the curriculum.

If $\mathrm{AD}$ (or HED or whatever other terminology may become current) is to grow fully into a more comprehensive, prominent and accountable role - as it should if it is to meet its obligations in improving educational effectiveness across the sector - there are important implications for the way it organises itself and for the development and dissemination of its knowledge and expertise. A good proportion of permanent AD specialists have responded to changing conditions in the universities - and to the stimulus of identifying with the growing international community of higher education scholars and researchers - by undertaking advanced studies and formal research in the area of educational development, so South African contributions to the international literature are increasing. As staff have achieved sufficiently senior academic status, a number of institutions are now able to offer master's and doctoral programmes in Higher Education Studies.

Research-on-research designed to understand the underlying theories, themes and directions of AD-related inquiry is needed but still in its infancy. The influences on AD have widened greatly over the last decade as AD staff have increasingly linked up with the international higher education scholarly community. Broad influence comes prominently from UK and Australasian scholarship - particularly in the sociology and philosophy of higher education (cf. writers such as Trowler, Knight, Bernstein, Barnett) - as well as from North America, and the Scholarship of Teaching and Learning (SoTL) movement is gaining currency. Educational and social theory continues to underlie much work. Phenomenography's dominant position in Europe and Australasia is increasingly critiqued. 
Perhaps because of AD's historical focus on subject teaching in foundational provision, a good proportion of educational development staff continue to identify primarily with discipline-specific educational theory and practice, such as Science or Health Education, or other specialised fields such as Applied Linguistics and the New Literacies. While there are obvious overlaps with the core of $A D$, the different allegiances show up in the kind of conferences AD staff participate in, the different literatures they consult, and the historical difficulty of establishing a common discourse among AD staff in the same institution. The differences can clearly be stimulating and critical of orthodoxies, but also present an interesting challenge for HELTASA. They also provide food for thought in conceptualising any future state-supported organisation for promoting research and development in teaching and learning.

This brief overview of the current stage of $A D$ omits much, but is intended to indicate some of the issues and challenges in the professional AD community itself. However, a fundamental element of the wider $A D$ agenda is that the goals of equity and development will not be met without mainstream systemic change in design and delivery, which in turn depends ultimately on behaviours, priorities and attitudes in the academic community at large. This key topic is addressed elsewhere in this volume but the following section offers a brief overview of the connections between AD and mainstream teaching.

\section{AD AND THE RECOGNITION OF 'TEACHING' IN HIGHER EDUCATION}

The progress of $A D$ has been strongly affected by the status of teaching in higher education. Moreover, given the importance of mainstream educational development for equity and development, the future of $A D$ and its goals is inextricably bound up with how the significance of the educational function of higher education is perceived, and what the consequences of this are for the recognition and rewarding, and thus the status, of teaching. It should be emphasised that 'teaching' here means engagement in all aspects of the educational process, from curriculum or programme development through course design to direct work with students.

In South Africa, as in many other parts of the world, the status of teaching in higher education has historically not been high across the sector. Evidence of this includes: there are few if any adequately resourced 'teaching development' operations in the institutions; the HEQC's Quality Promotion and Capacity Development directorate, which is still at an early stage of development itself, is the only statutory body with a mandate to improve teaching and learning; there are no state-funded national 
organisations or infrastructure for supporting educational research and development; and the perception that only certain forms of published research bring academic career advancement is rarely contradicted. There are in fact indications that teaching is being further neglected as a result of the new institutional 'landscape', in that the universities of technology and to some extent the comprehensive universities are concentrating on building up conventional research cultures, often from a low base.

The low status of teaching contrasts sharply with the pressing need to improve the educational effectiveness of the sector, and the consequences for the country if this is not done. There may be many contributory factors, including the rapidity of change in the institutions and the student body, but on the evidence of the performance patterns, current mainstream approaches to design and delivery are not meeting the national need. In the South African context where the majority are affected by educational disadvantage, educational development cannot be left only to AD specialists.

Both $A D$ (as a specialism) and mainstream teaching are thus trying to emerge from marginalisation. The question of what it would take for teaching to be properly recognised as a legitimate and valued academic activity is a key strategic concern. Discussion of this complex matter is outside the scope of this chapter, but the literature and $A D$ experience suggest the following key points:

It is in the first instance essential that teaching be given greater 'attention' (Carey 2008) - that is, enjoy the care and effort that the importance of the educational function of higher education in a developing country calls for. This is most unlikely to happen without a significant shift in the dominant higher education value and reward system. Such a shift should not mean underrating the key role of research in development; however, while many university mission statements assert the interlinkage between research and teaching, in practice many academics experience the relationship as a stressful tension rather than one of mutual strengthening, and teaching suffers as a result. ${ }^{11}$ Since the dichotomy between research and teaching that has been created by current reward systems is highly undesirable, the goal must be to achieve a productive balance, based on respect for these different expressions of scholarship and, in particular, full appreciation of the significance of both in our developing country context.

'Attention', however, is not enough in itself. It is evident from institutional data, local experience and the national performance patterns that the traditional teaching approaches that are predominant in South Africa have proved less than adequate in

11 For an interesting range of perspectives on this topic, see Marwell (2007). 
facilitating quality learning in the majority of the student body. The craft knowledge underlying these approaches appears to lack the capacity to produce effective responses to educational disadvantage and the diversity of the student body in many institutions. What is called for is raising the level of educational 'expertise' (Kreber 2002) - that is, systematic knowledge of teaching-and-learning theory and practice. Such expertise is necessary for effectiveness not only in curriculum and course design but also in daily practice in the lecture hall, as well as in the real or virtual classroom. It should provide academic teaching staff with the conceptual tools to understand and adapt to new conditions for which their prior experience has not equipped them.

Promoting educational expertise also calls for changes in the material reward system, but this is not enough. Engaging academics' intellectual interest in teaching and learning, and achieving respect for the educational process as an academically challenging area of inquiry, are also necessary conditions for educational expertise to prosper and expand. This depends on awareness of the growing body of higher education theory and research literature, and particularly on the visibility of examples of successful teaching and learning that are informed by sound research. AD specialists no doubt need to play a leading role in working to establish a theorised environment for educational development, but the wider aim is to extend the scholarship of teaching and learning into the mainstream of the universities. This is not to say that all academic staff should become educational specialists; the goal is rather to ensure that an appropriate level of educational expertise is present in departments and programme teams and that the expertise is credible and respected enough to be effectively utilised.

There is a risk of unintended consequences in building an academic basis for educational development, namely that the connection between research and development may become increasingly tenuous, opening up the old fault-line (still present as a residual tension) between 'activist' and academic orientations. To a South African eye, this kind of division exists today in some developed countries - manifested in the USA, for example, in the organisational and academic distance between prominent higher education studies departments and minority education programmes in one or other form; or in England, between such departments and Widening Participation units. The concern is that in these circumstances, the research available is not well utilised by developmental operations on the ground, and the researchers do not see it as their function to become involved in development. Educational scholarship and research then have little if any impact on practice, and therefore on outcomes. In the context of South Africa (and no doubt other developing countries), this could well be seen as misdirection of scarce resources and losing sight of the overarching needs. In this 
context, it seems justifiable to try to focus educational research and development energy on the central goal of improving the effectiveness of teaching and learning across the sector, in terms of quality, inclusiveness and responsiveness to contemporary conditions.

\section{IN CONCLUSION: THE AD PERSPECTIVE}

This chapter has argued that $A D$, or rather what it represents, continues to be a major issue in South African higher education, and will if anything have growing significance as the elusiveness of equity and transformation strains the country's patience. Also, to revisit the theme raised earlier, the chapter has attempted to outline the situation that gives rise to the $A D$ perspective on the higher education sector, which contrasts uncomfortably with others in terms of priorities and orientation. What then is that perspective?

When the higher education sector is seen through an $A D$ lens, it seems clear that there is something fundamentally wrong at the heart of it. A system that is not able to successfully accommodate more than $5 \%$ of the majority population group is failing in a critical way. In contrast with the position in most other African countries, the shortcoming cannot be attributed in any simple way to lack of material resources, given that a very respectable proportion of GDP is allocated to higher education. In fact, HSRC researchers have estimated that state subsidy spent on students who fail or drop out currently amounts to over R3 billion a year (Letseka and Maile 2008). While socio-economic and schooling conditions are clearly a major factor, the performance patterns and $A D$ experience indicate that in key respects the sector is misaligned with the realities of its host society, and is not contributing adequately to what the country probably most needs from it, that is, good graduates in appropriate numbers from all communities. This is a central purpose of higher education - arguably the main one in developing countries - and failure to achieve it on the present scale diminishes successes in other aspects of the sector's role. In these circumstances, important debates on matters ranging from governance to world trends in curricula can have a hollow ring.

At the heart of the matter is the identity of the sector as a whole and the academic community in particular. The main identity tension affecting both the universities and individual academic staff is much the same, and is not surprising. An acceptance of the responsibility to meet local needs, particularly through undergraduate teaching, co-exists with, but is commonly outweighed by, the strong desire to be successful in the 
international world of scholarship, with all the intellectual, reputational and material rewards this brings. While mission statements declare institutional commitment to both these goals, the sector's performance patterns suggest otherwise; and formal and informal discourse in universities of all kinds on the 'burden' of dealing with the disadvantaged majority underlines the understandable but at present unequal contest.

This depiction of the sector is a disturbing one. However, the AD perspective at the same time provides a view of key measures that may make a substantial difference to effectiveness and inclusiveness, and are also within the power of the sector to implement. Curriculum reform of the kind outlined earlier is challenging but feasible, and if it were to save even a third of the 'wastage' in the system, affordability should not be an obstacle. It is feasible for the institutions to recognise the critical contribution of effective teaching and educational development to their core business, to introduce reward systems that stimulate educational effort and expertise, and through their recruitment and promotion systems to gather staff with complementary knowledge and skills of the kind that are necessary to deliver programmes and research that meet contemporary needs. It is also possible for the state and the institutions to agree on a form of mutual accountability for the outcomes of higher education that is founded on the importance of meeting national needs and the provision of resources to do so. If this can be done, the way can be opened to establishing a productive linkage between teaching and research, equity and development, and local and international obligations, which can go a good way towards addressing the 'frustration and sense of powerlessness' (Bitzer, Preface in this volume) that result from the unresolved tensions so commonly experienced by academics in South Africa.

To come back to AD itself, its primary challenge as a specialised field will probably be to continue strengthening the academic and professional foundations of its work at the same time as taking forward the educational development agenda in concrete forms: in policy advocacy and planning and in supporting implementation at sector and institutional level. Major forthcoming projects that AD will hopefully be centrally involved in - or that $A D$ should strongly advocate as priorities on the national agenda - include: (a) structural curriculum reform of the kind discussed earlier; (b) the establishment of state-sponsored national, regional and institutional structures and networks that support professional development in teaching, educational research and educational expertise in higher education; (c) continuing the development and expanding the use of alternative student selection and placement instruments that assess academic potential rather than only achieved performance, so that talented but 
disadvantaged students can be identified and admitted at an entry level that matches their learning needs. ${ }^{12}$

If $A D$ is to position itself to address these challenges effectively, there are implications for its own development agenda, including the following:

- If the AD perspective is to have a positive influence on the sector, the scholarship and research (quantitative and qualitative) that back it must continue to be strengthened. This means that the residual tension between the activist and academic orientations in $A D$ needs to be openly debated, to improve understanding of the different roles and particularly the relationship between research-for-policy, research-onpolicy, and the wider field of SoTL. A fundamental question here is to what extent educational research and SoTL will have the capacity to inform higher education development in such a way as to make a substantial difference to who benefits from higher education, particularly in contexts like South Africa where the significance of improvement of outcomes is so high (Scott 2009a).

- It can be expected that opportunities or calls for AD to embrace more radical pedagogies or educational agendas will arise more frequently than has been the case. While the involvement of AD specialists in such developments should depend on their knowledge base and the merits of the case, more open debate and writing about the character and fitness of purpose of South Africa's mainstream curricula would add an additional critical dimension to educational development that could stimulate specialists and mainstream academics alike and ensure that $A D$ does not artificially confine itself within a 'technicist' approach (Clegg 2009).

- As the scope of AD has widened, more and more common ground has been found with similar fields abroad, not just academic development itself (in the British and Australasian sense), but a range of areas of higher education studies. However, most of the interaction has been with English-speaking first world countries. The time may well have come for AD to widen its horizons by actively seeking engagement with systems in the global South or other emerging economies - such as India, South American and Eastern European countries, and other African countries where challenges and constraints are similar to our own.

12 The complex topic of approaches to student selection and placement has been only superficially referred to in this chapter, but is a key element of successful curriculum reform. It is bound up with the question of who higher education in South Africa is for, and has key implications for responsible approaches to widening participation. 
It is commonly noted in South Africa that there is little if any AD, as we know it, in other sub-Saharan African countries. This may be the case, because higher education systems in these countries have historically been very small (GER averages 5\%) and highly selective. However, the situation is changing rapidly: higher education enrolment is increasing at $15 \%$ a year, the highest rate in the world (Africa Higher Education 2008), with much of the growth occurring in new private institutions, generating considerable problems of quality assurance and regulation. In these circumstances, and with class, ethnic or regional inequalities being chronic, widening participation is likely to be very challenging, and it would be surprising if the same kind of issues as affect South Africa (albeit not racially based) were not already arising. The next decade may thus offer a unique period of opportunity to engage with other parts of the continent, with mutual benefit and enrichment.

The situation of higher education in South Africa has features that create special difficulties, but at the same time make it an unusually interesting and significant area for research and creativity in educational development. In contrast with developed countries, educational disadvantage here is a majority phenomenon. In contrast with other African countries, the South African system is large and highly diverse, and there is a 30-year history of experience and experimentation with educational development, much of it in adverse conditions. Educationists in South Africa, both inside and outside of $A D$, are consequently in a good position to contribute to the theorisation of teaching and learning in higher education, to undertake sound empirical work, to implement innovative educational approaches, to influence the sector, and to interact constructively with colleagues and organisations in other countries. The extent to which this will happen depends much on how seriously national bodies and the sector itself take up the challenges of equity and development that are becoming increasingly visible and pressing.

\section{ACKNOWLEDGEMENT}

To Kalie Strydom: for marrying research and development better than anyone else in the first decades of $A D$, in which work he was selflessly and most ably partnered by Alida; for true courage in not resting content with a pioneering role in developing higher education scholarship, but also engaging an often hostile environment and producing innovative development on the ground, which has benefited many thousands of students over the years; and for giving generous developmental opportunities to inexperienced entrants to the higher education field, including this writer. 


\section{REFERENCES}

Africa Higher Education. 2008. Higher Education in Sub-Saharan Africa [Online]. Available: http://www.arp.harvard.edu/AfricaHigherEducation/Data.html [2008, 7 December].

Agar D. 1994. Universities and the academic profession: Implications for change. SA Journal of Higher Education, 8(2):5-8.

Badat S. 2009. Theorizing Institutional Change: Post-1994 South African Higher Education. Forthcoming in special edition of Studies in Higher Education.

Bitzer EM. 2009. Preface to this volume.

Bloch G. 2008. Fixing schools: A 30-year task. Pretoria News, 31 July: 12 [Online]. Available: http://www.iol.co.za/index.php?set_id=1\&click_id=13\&art_

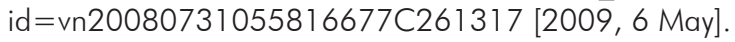

Boughey C. 2008. Educational Development in South Africa: From social Reproduction to Capitalist Expansion? Higher Education Policy, 20:5-18.

Carey K. 2008. Graduation Rate Watch: Making Minority Student Success a Priority. Washington DC: Education Sector [Online]. Available: http://www.educationsector.org/ usr_doc/Graduation_Rate_Watch.pdf [2009, 5 May].

Clegg S. 2009. Histories and institutional change: Understanding academic development practices in the global 'north' and 'south'. International Studies in the Sociology of Education, 16. In press.

Cooper D \& Subotzky G. 2001. The Skewed Revolution: Trends in South African Higher Education. Bellville: Educational Policy Unit, University of the Western Cape.

DoE (Department of Education). 1997. Education White Paper 3: A Programme for the Transformation of Higher Education. Pretoria: Government Gazette, No. 18207. 15 August.

DoE (Department of Education). 2001. National Plan for Higher Education. Pretoria: Department of Education.

DoE (Department of Education). 2003. Funding of Public Higher Education. Schedule to the Higher Education Act (Act No. 101 of 1997). Pretoria: Department of Education. November.

DoE (Department of Education). 2006. Funding for foundational provision in formally approved programmes: 2007/08 to 2009/10.

DoE (Department of Education). 2009. Education Statistics in South Africa 2007. Pretoria: Department of Education.

Feverstein R. 1980. Instrumental enrichment: An intervention program for cognitive modifiability. Baltimore: University Park Press.

HEQC. 2007. HEQC Institutional Audits Manual. Pretoria: Council on Higher Education.

Hofmeyr J \& Spence R. 1989. Bridges to the Future. Optima, 37(1):37-48.

Hunter P. 1991. Academic support or mainstream change? SA Journal of Higher Education, 5(2):5-6. 


\section{PART ONE • ISSUES OF POLICY}

Kreber C. 2002. Teaching excellence, teaching expertise, and the scholarship of teaching. Innovative Higher Education, 27(1):5-23.

Lazarus J, Miller R, Moll I, Slonimsky L \& Craig A. 1989. New students in old universities: Cognitive development in the South African tertiary education context. SA Journal of Higher Education, 3(1):153-172.

Letseka M \& Maile S. 2008. High university drop-out rates: A threat to South Africa's future: HSRC policy brief. March edition. Pretoria: Human Sciences Research Council.

Marwell P. 2007. Papers from an international colloquium: International policies and practices for academic enquiry [Online]. Available: http://portal-live.solent.ac.uk/university/ itconference/2007/colloquium_papers.aspx [2009, 5 May].

Mehl MC. 1988. Academic Support: Developmental giant or academic pauper? SA Journal of Higher Education, 2(1):17-20.

Moulder J. 1991. Remedial education programmes: Miracle or failure? SA Journal of Higher Education, 5(1):5-10.

Perkins D. 1986. Knowledge as Design. Hillsdale, New Jersey: Lawrence Erlbaum Associates.

Piaget J. 1972. Intellectual development from adolescence to adulthood. Human Development, 15:1-12.

SAAAD (South African Association for Academic Development). 1995. Facilitating Academic Development as a key element of transformation in Higher Education. Submission to the National Commission on Higher Education by the SA Association for Academic Development. Johannesburg: SAAAD.

Scott I. 1986. Tinkering or transforming? The contribution of academic support programmes to 'opening the doors of learning and of culture'. Aspects 7. Pietermaritzburg: University of Natal.

Scott I. 2009a. Towards an Agenda for SoTL in Africa? International Journal for the Scholarship of Teaching and Learning, 3(1), January 2009 [Online]. Available: http://academics. georgiasouthern.edu/ijsotl/v3n1.html [2009, 28 Apri].

Scott l. 2009b. Who is 'getting through' in South Africa? Implications for the reconstruction of the formal curriculum. In: D Featherman, M Hall \& M Krislov (eds). The Next Twenty Five Years? Affirmative Action and Higher Education in the United States and South Africa. University of Michigan Press. Forthcoming.

Scott I. 2009c. First-year experience as terrain of failure or platform for development? Critical choices for higher education. In: B Leibowitz, A van der Merwe \& S van Schalkwyk (eds). Focus on First-year Success. Stellenbosch: SUN MeDIA. Forthcoming.

Scott I, Yeld N \& Hendry J. 2007. A case for improving teaching and learning in South African higher education. Higher Education Monitor No. 6. Pretoria: Council on Higher Education [Online]. Available: http://www.che.ac.za/documents/d000155/index.php [2009, 21 April].

Scott I, Yeld N, McMillan J \& Hall M. 2005. Equity and excellence in higher education: The case of the University of Cape Town. In: GB William, AM Kurzweil \& EM Tobin (eds). Equity and Excellence in American Higher Education. Charlottesville, VA: University of Virginia Press. Thomas Jefferson Foundation Distinguished Lecture Series. 
UNESCO. 2007. Education For All Report 2008. Paris: UNESCO.

Van der Berg S. 2004. School education and transformation [Online]. Available: http://transf. audit.co.za/articles/education/pdf [2009, 4 May].

Vilakazi H \& Tema B. 1985. White Universities and the Black Revolution. Paper presented at the 1985 Academic Support Programmes Conference. Johannesburg: University of the Witwatersrand.

Vygotsky L. 1978. Mind in society: The development of higher mental processes. Cambridge: Harvard University Press.

Wolpe H, Badat S \& Barends Z. 1993. The post-secondary education system: Beyond the equality vs. development impasse and towards policy formulation for equality and development. Cape Town: Education Policy Unit, University of the Western Cape.

Yeld N. 2009. Getting In: Admissions Policies. In: D Featherman, M Hall \& M Krislov (eds). The Next Twenty Five Years? Affirmative Action and Higher Education in the United States and South Africa. University of Michigan Press. Forthcoming. 